\title{
Humberto Mauro e o cinema como construção da memória
}

\author{
Paola Prestes Penney
}

MORETTIN, E.

Humberto Mauro, Cinema, História.

São Paulo: Alameda Casa Editorial.

494 p., 2013.

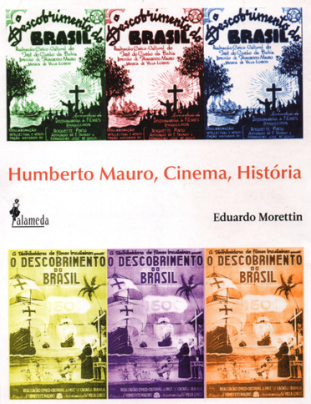

Resumo: Em Humberto Mauro, Cinema, História, dois filmes de Humberto Mauro são analisados e articulados com o contexto histórico em que foram realizados. Dessa forma, é exposta a relação entre arte, cultura e poder no Brasil e, mais especificamente, de que maneira se dá a monumentalização do passado por meio de uma iconografia que tem por fim se tornar a própria memória nacional.

Palavras-chave: Humberto Mauro; cinema; história; Ince.

Abstract: Humberto Mauro and cinema as the construction of memory - The book "Humberto Mauro, Cinema, History" analyzes two films by Humberto Mauro and links them with the historical context in which they were produced. Thus, it reveals the relationship between art, culture and power in Brazil, and more specifically, how the past is monumentalized through an iconography aimed at becoming the very memory of a nation.

Keywords: Humberto Mauro; cinema; history; Ince.

Em Humberto Mauro, Cinema, História, Eduardo Morettin estuda dois filmes de Humberto Mauro: o longa-metragem Descobrimento do Brasil (1937) e o curta-metragem Os Bandeirantes (1940). A análise fílmica das obras é revestida por uma pesquisa 
histórica que lhe confere organicidade e sentido dentro de um contexto que diz respeito à história do Brasil e à construção de uma memória comum de contornos nacionais. Assim, é possível ler o livro como um trabalho acadêmico - que é de fato sua origem -, mas essa é certamente apenas uma das leituras que o texto oferece.

Há três momentos significativos na carreira de Humberto Mauro: o ciclo de Cataguases nos anos 1920, a produção nos estúdios da Cinédia, em meados dos anos 1930, e os cerca de trezentos filmes feitos sob a égide do Instituto Nacional de Cinema Educativo, o Ince, a partir de 1936. O segundo momento é uma decorrência natural do primeiro, porém, ao ser convidado por Edgard Roquette-Pinto para ser diretor técnico do Ince, a trajetória de Mauro toma um rumo diferente: ele passa a realizar filmes institucionais, entre eles Descobrimento do Brasil e Os Bandeirantes. O interesse desse percurso é revelado pela pesquisa de Morettin, que trata precisamente do momento em que Mauro deixa para trás sua produção de ficções, essencialmente tramas românticas e até musicais, para fazer filmes de encomenda com um propósito explicitamente edificante, educativo e moralmente formativo.

Descobrimento do Brasil e Os Bandeirantes ficam aquém dos objetivos almejados por seus financiadores e mentores intelectuais. No entanto, as deficiências que Morettin aponta não se esgotam em questões meramente cinematográficas: expõem áreas sensíveis da relação entre arte, cultura e poder no Brasil, a começar pelo tratamento recebido por Mauro que, de cineasta com autonomia criativa, passa à condição de técnico com a função de dar uma forma audiovisual ao programa ideológico de intelectuais como Affonso de Taunay.

Não menos importante, Taunay vale-se da estrutura do Ince, fundado pouco antes da instauração do Estado Novo e vinculado ao Ministério da Educação e Cultura (mais tarde Ministério da Educação e Saúde), para colocar em prática um projeto de construção histórica que, convenientemente, serve tanto aos propósitos do recém-criado Museu Paulista, do qual é diretor, como ao governo ditatorial de Getúlio Vargas. Por exemplo, o projeto que Taunay tem para o museu, de criar e difundir uma iconografia heroica e virtuosa encarnada pelos fundadores da nação brasileira - os navegantes descobridores, os bandeirantes desbravadores e os feitos destes últimos pelo interior do Brasil -, amolda-se e serve ao movimento de ocupação econômica do interior do Brasil que tem início com a Marcha para o Oeste.

A transição de Mauro expõe um segundo nervo, o momento em que o cinema, até então considerado pela intelligentsia brasileira como uma atividade de entretenimento menor e até moralmente indigna, é redimido ao ser visto tanto por essa classe como pelo governo como possível ferramenta pedagógica, legitimadora da história, transmissora de valores morais, em grande escala, e, sobretudo, como propaganda do poder vigente. Cria-se, assim, um projeto de produção já de antemão comprometido com as instâncias que o precedem: Mauro é contratado por conhecer a linguagem cinematográfica sem, todavia, ganhar liberdade para fazer de fato cinema, sujeitando-se, do roteiro às referências iconográficas, a toda sorte de ingerências por parte de quem o contratou. 
Não por rebeldia, Mauro não faz os filmes esperados e, pelo que se depreende do texto de Morettin, não o faz apesar de si próprio. Os propósitos que estão na base dos projetos dos filmes - a encenação de um passado monumental que justifica e prepara o terreno para o futuro glorioso da Pátria brasileira - são obliterados pelo tom melancólico que permeia de modo geral a obra do diretor. O resultado é opaco demais para configurar um fracasso de imediato, e, em meio a heróis de natureza tão ambígua quanto a de suas conquistas, pode-se dizer que o cineasta triunfa às avessas na medida em que imprime sua marca às histórias que filma pelas frestas das diretrizes que lhe foram impostas.

O último nervo - o mais abrangente e grave - diz respeito à relação histórica entre o poder, a arte e a cultura no Brasil. Fica patente, no texto de Morettin, a necessidade de afirmar, já desde o academicismo, o Brasil por meio de uma construção iconográfica como nação ilustre no compasso de países mais desenvolvidos. Nesse ponto, alinham-se as elites da República Velha a Getúlio Vargas. Talvez toda história seja de fato construção, mas, no Brasil, essa afirmação deve vir rapidamente e de forma inequívoca a fim de compensar a ausência do lastro que o tempo confere à história de um país. Em sua urgência, as elites dos anos 1930-1940 e o governo de Getúlio Vargas lançaram mão de uma prática que assombra a produção artística brasileira até hoje, a de não fomentar a arte em si, permitindo que ela sedimente uma cultura nacional sólida e madura.

$\mathrm{Na}$ época, o cinema sequer era considerado arte e, sem dramas de consciência, Humberto Mauro foi obrigado pelas instituições que o contrataram a fazer de seu ofício uma ferramenta de propaganda a serviço de ideologias ou da ideia que as elites e o governo gostariam que o resto do mundo tivesse a respeito do Brasil. Como não enxergar um paralelo entre a subordinação de Mauro às vontades do governo, de intelectuais e até de empresários, como os senhores latifundiários do Instituto do Cacau da Bahia (ICB) que financiaram Descobrimento do Brasil? E a condição de um cineasta contemporâneo que, para produzir, deve sujeitar-se às regras de um aparato governamental, agradar aos patrocinadores e conformar seus projetos cinematográficos ao direcionamento de natureza social e educativa, que subjaz os editais públicos e de empresas?

É nesse sentido que Humberto Mauro, Cinema, História ultrapassa as fronteiras da análise fílmica ou do relato histórico: apontando para a crise crônica do relacionamento entre arte, cultura e poder, e colocando a inquietante questão acerca dos rumos do cinema no Brasil.

Paola Prestes Penney é doutoranda em Comunicação e Semiótica na PUC-SP. É professora na pós-graduação em Cinema Documentário da Fundação Getúlio Vargas, FGVSP e, desde 2012, ministra os cursos de documentário do Museu da Imagem e do Som, MIS-SP. É documentarista pela Serena Filmes, tendo participado da Mostra Internacional de Cinema da São Paulo.

paola@serenafilmes.com.br 